\title{
Alterações hematológicas, hemostáticas e bioquímicas induzidas pela clofazimina e claritromicina, em doses única e múltiplas, em ratos
}

\author{
Hematological, hemostatic and biochemical alterations induced \\ by clofazimine and clarithromycin, in single \\ and multiple doses, in rats
}

Flávia Aparecida Paina ${ }^{1}$, Regina Helena Costa Queiroz $^{1}$ e Ana Maria de Souza ${ }^{1}$

\begin{abstract}
RESUMO
Claritromicina e clofazimina têm sido utilizadas no tratamento da hanseníase, tuberculose e infecções causadas pelo complexo Mycobacterium avium. Como os dados sobre a toxicidade de esquemas terapêuticos que incluem estes fármacos são escassos, este estudo teve como objetivo determinar os efeitos adversos destas terapias, por meio da avaliação dos parâmetros hematológicos, hemostáticos e bioquímicos. Os fármacos foram administrados em ratos machos Wistar, em monoterapia, em regime de doses única e múltipla. Claritromicina provocou aumento de leucócitos mono e polimorfonucleares. Ambos os fármacos inverteram a proporção entre células mono e polimorfonucleares e provocaram aumento do número de células polimorfonucleares e células em degeneração. Clofazimina e claritromicina prolongaram o tempo de protrombina e claritromicina também prolongou o tempo de tromboplastina parcial ativa. Claritromicina causou aumento de bilirrubinas total e direta e, ambos os fármacos, elevaram os níveis plasmáticos de gama-glutamiltransferase. Portanto, clofazimina e claritromicina induzem alterações hematológicas, hemostáticas e hepáticas.
\end{abstract}

Palavras-chaves: Alterações hematológicas. Clofazimina. Claritromicina. Mycobacterium avium.

\begin{abstract}
Clarithromycin and clofazimine have been used to treat leprosy, tuberculosis and infections caused by the Mycobacterium avium complex. Since there is a scarcity of data on the toxicity of therapeutic regimens that include these drugs, this study had the aim of determining the adverse effects of these therapies, through evaluation of hematological, hemostatic and biochemical parameters. The drugs were administered to male Wistar rats, as monotherapy, in regimens of single and multiple doses. Clarithromycin caused increases in the numbers of mononuclear and polymorphonuclear leukocytes. Both of the drugs inverted the proportions between mononuclear and polymorphonuclear cells and increased the numbers of polymorphonuclear cells and degenerating cells. Clofazimine and clarithromycin prolonged the prothrombin time and clarithromycin also prolonged the activated partial thromboplastin time. Clarithromycin caused increases in total and direct bilirubin. Both of the drugs increased the plasma levels of gamma-glutamyltransferase. Therefore, clofazimine and clarithromycin induce hematological, hemostatic and hepatic changes.
\end{abstract}

Key words: Hematological changes. Clofazimine. Clarithromycin. Mycobacterium avium.

A investigação de efeitos adversos provocados por fármacos é fundamental visto que os medicamentos podem interferir em vários mecanismos de diferenciação e especialização celular, inclusive na produção de células sangüíneas, que é finamente regulada e representa papel relevante nas funções vitais do organismo.

A combinação de clofazimina e claritromicina tem sido utilizada no tratamento de infecções causadas pelo complexo
Mycobacterium avium, que são comuns em pacientes portadores do vírus da imunodeficiência humana (HIV) ${ }^{8}$. Além disso, ambos os fármacos são utilizados no tratamento da hanseníase ${ }^{926}$ doença que, apesar de todo avanço científico e tecnológico, ainda se mantém prevalente nos dias atuais, constituindo um problema de saúde pública no Brasil ${ }^{11}$. Claritromicina também é utilizada em monoterapia no tratamento de infecções do trato respiratório e

1. Departamento de Análises Clínicas, Toxicológicas e Bromatológicas, Faculdade de Ciências Farmacêuticas de Ribeirão Preto, Universidade de São Paulo, São Paulo, SP. Apoio financeiro: CAPES

Endereço para correspondência: Dra Flávia Aparecida Paina. Dept ${ }^{0}$ de Análises Clínicas, Toxicológicas e Bromatológicas/FCFRP/USP. Av. do Café s/n, Sala 053-A Bloco M, Campus Universitário, 14040-903 Ribeirão Preto, SP.

Tel: 55 16 3602-4204; Fax: $55163633-1092$.

e-mail: flaviapaina@yahoo.com.br

Recebido para publicação em: 09/10/2007

Aceito em: 02/06/2008 
tem sido indicada, em esquema de politerapia, para erradicação do Helicobacter pylori ${ }^{15}$.

Alguns estudos têm relatado efeitos adversos provocados por ambos os fármacos. Com relação à claritromicina, os efeitos mais comuns envolvem o trato digestivo, como diarréia, náusea, alterações no paladar, dispepsia e desconforto abdominal. Podem ocorrer ainda candidíase oral, estomatite, vômitos, flatulência, constipação, descoloração da língua, pancreatite e laringismo ${ }^{17}$. Com menor freqüência, ocorrem colestase hepática, erupções cutâneas, ototoxicidade com surdez temporária e alterações neurológicas ${ }^{15}$. Foram observados ainda elevação dos níveis plasmáticos de aspartato aminotransferase (AST), alanina aminotransferase (ALT), fosfatase alcalina, lactato desidrogenase ( $\mathrm{LDH}$ ) e/ou bilirrubina total, hepatomegalia e disfunção hepática, incluindo colestase com ou sem icterícia, em pacientes recebendo claritromicina isoladamente ou em combinação com omeprazol ${ }^{6}$. Foi observada ainda elevação da concentração plasmática de creatinina em menos de $1 \%$ de pacientes que receberam o fármaco, isolado ou combinado com omeprazol e disfunção renal agud $a^{24}$. Com relação aos parâmetros hematológicos, pesquisadores observaram prolongamento do tempo de protrombina (TP), leucopenia e trombocitopenia em cerca de $1 \%$ dos pacientes $^{24}$. Um estudo relatou um caso fatal de anemia aplástica induzida pelo fármaco ${ }^{2}$, ao passo que em outro foi observado aumento na contagem de plaquetas de três pacientes com púrpura trombocitopênica idiopática tratados com claritromicina ${ }^{14}$.

A clofazimina é um fármaco altamente lipofílico que se acumula no tecido adiposo e células do sistema reticuloendotelial ${ }^{10}$. Os efeitos adversos gastrointestinais são os principais limitantes da dosagem, devido à deposição de cristais de clofazimina na mucosa intestinal ${ }^{13}$. Pode causar coloração avermelhada da pele, suor e lágrimas e fotossensibilidade ${ }^{13}$. Um estudo realizado com 45 pacientes com hanseníase tratados com clofazimina detectou a ocorrência de metemoglobinemia e anemia hemolítica somente quando havia associação da clofazimina com dapsona e rifampicina ${ }^{19}$.

Embora os relatos sobre a eficácia sejam satisfatórios, as informações sobre a toxicidade de esquemas terapêuticos que incluam clofazimina ou claritromicina são escassas. Assim, neste estudo, nos propusemos a investigar os possíveis efeitos adversos destas terapias, em regimes de doses única e múltipla, por meio da avaliação dos parâmetros hematológicos, hemostáticos e da função hepática, em ratos machos Wistar.

\section{MATERIAL E MÉTODOS}

Foram utilizados ratos machos jovens, da linhagem Wistar, pesando entre 220 e $250 \mathrm{~g}$. 0 trabalho foi aprovado pelo Comitê de Ética no Uso de Animais do Campus de Ribeirão Preto (USP). Os animais foram assim divididos: grupos controles $\mathrm{NaCl} 0,9 \%$ e dimetilsulfóxido (DMSO), grupo clofazimina nas doses de 50, 100 e $200 \mathrm{mg} / \mathrm{kg}$ de peso corpóreo; grupo claritromicina nas doses de 50, 100 e 200mg/kg de peso corpóreo, em regime de dose única. Para o regime de dose múltipla, foi utilizada apenas a dose intermediária de $100 \mathrm{mg} / \mathrm{kg}$, sendo administrada, a cada 24 horas, durante 4 dias consecutivos. Os fármacos e os controles foram administrados via intraperitoneal e a coleta das amostras de sangue foi realizada após 2 horas da administração, em regime de dose única, e após 24 horas da última dose, em regime de dose múltipla.

Foram avaliados os seguintes parâmetros hematológicos: número de eritrócitos, leucócitos e plaquetas (método manual), concentração de hemoglobina (método cianometahemoglobina colorimétrico), hematócrito (método microhematócrito), cálculo dos índices eritrocitométricos, fórmula leucocitária (extensão sanguínea corada com May-Grünwald/Giemsa) e contagem de reticulócitos (azul de cresil brilhante), em sangue total anticoagulado com ácido etilenodiamino tetra-acético (EDTA). A avaliação hemostática incluiu a determinação do tempo de protrombina (TP) ${ }^{20}$ e do tempo de tromboplastina parcial ativada (TTPA) ${ }^{3}$, em plasma obtido de sangue anticoagulado com citrato de sódio, utilizando kits comerciais da marca Wiener. $\mathrm{Na}$ avaliação bioquímica (perfil hepático) foram determinados os níveis plasmáticos da aspartato aminotransferase ${ }^{21}$ (AST) e alanina aminotransferase ${ }^{21}$ (ALT), com reagentes Labtest (Labtest Diagnóstica, MG, Brasil), fosfatase alcalina ${ }^{4}$, gamaglutamiltransferase ${ }^{23}\left(\gamma\right.$-GT) e bilirrubinas ${ }^{22}$ direta e total, com reagentes Bayer (Bayer, Produits Diagnostics, France), utilizando-se o analisador automático modelo Opera Chemistry da Bayer (Bayer Corporation, Tarrytown, USA), através de métodos cinéticos e/ou colorimétricos, em plasma obtido de sangue anticoagulado com heparina.

Os dados foram analisados aplicando-se o teste de normalidade, com auxílio do programa GMC, e o teste não paramétrico de Kruskal-Wallis, seguido do pós-teste de Dunns, utilizando o programa GraphPad Prism ${ }^{\circledR}$. 0 nível de significância estabelecido foi $\mathrm{p}<0,05$.

\section{RESULTADOS}

Parâmetros hematológicos. Clofazimina e claritromicina não ocasionaram alterações estatisticamente significantes no número de eritrócitos, concentração de hemoglobina, hematócrito, contagem de reticulócitos, volume corpuscular médio (VCM), hemoglobina corpuscular média (HCM) e concentração de hemoglobina corpuscular média (CHCM) (FA Paina, RHC Queiroz, AM Souza: dados não publicados). Foram observadas alterações morfológicas nos eritrócitos, tanto em ratos tratados com clofazimina como com claritromicina, apenas em regime de dose múltipla (Tabela 1).

A clofazimina causou aumento apenas do número de leucócitos polimorfonucleares, tanto em dose única (Figura 1A) como em dose múltipla (Figura 1B), embora significância estatística tenha sido observada apenas na maior dose única utilizada. A contagem total de leucócitos e o número de células mononucleares permaneceram sem alterações (FA Paina, RHC Queiroz, AM Souza: dados não publicados). Claritromicina causou aumento do número de leucócitos (Figura 1C) e de células 
Tabela 1 - Porcentagem de animais com alterações morfológicas nos eritrócitos do sangue periférico, tratados com clofazimina na dose de 100mg/kg e claritromicina na dose de 100mg/kg, em esquema de dose múltipla.

\begin{tabular}{lcccc}
\hline Condições morfológicas & $\begin{array}{c}\text { NaCl 0,9\% } \\
\left(\mathrm{n}^{-0}=10\right)\end{array}$ & $\begin{array}{c}\text { DMSO } \\
\left(\mathrm{n}^{\circ}=10\right)\end{array}$ & $\begin{array}{c}\text { CFZ 100 } \\
\left(\mathrm{n}^{0}=9\right)\end{array}$ & $\begin{array}{c}\text { CRT 100 } \\
\left(\mathrm{n}^{0}=9\right)\end{array}$ \\
\hline Normocromia, poiquilocitose e anisocitose discretas & 100 & 100 & 77,8 & 77,8 \\
Normocromia, poiquilocitose e anisocitose moderadas & 0 & 0 & 0 & 22,2 \\
Hipocromia discreta, poiquilocitose e anisocitose discretas & 0 & 0 & 0 & 0 \\
Hipocromia discreta, poiquilocitose e anisocitose moderadas & 0 & 11,1 & 0 \\
\hline
\end{tabular}

NaCl 0,9\%: cloreto de sódio 0,9\%, DMSO: dimetilsulfóxido, CFZ 100: clofazimina na dose de 100mg/kg, CRT 100: claritromicina na dose de 100mg/kg.

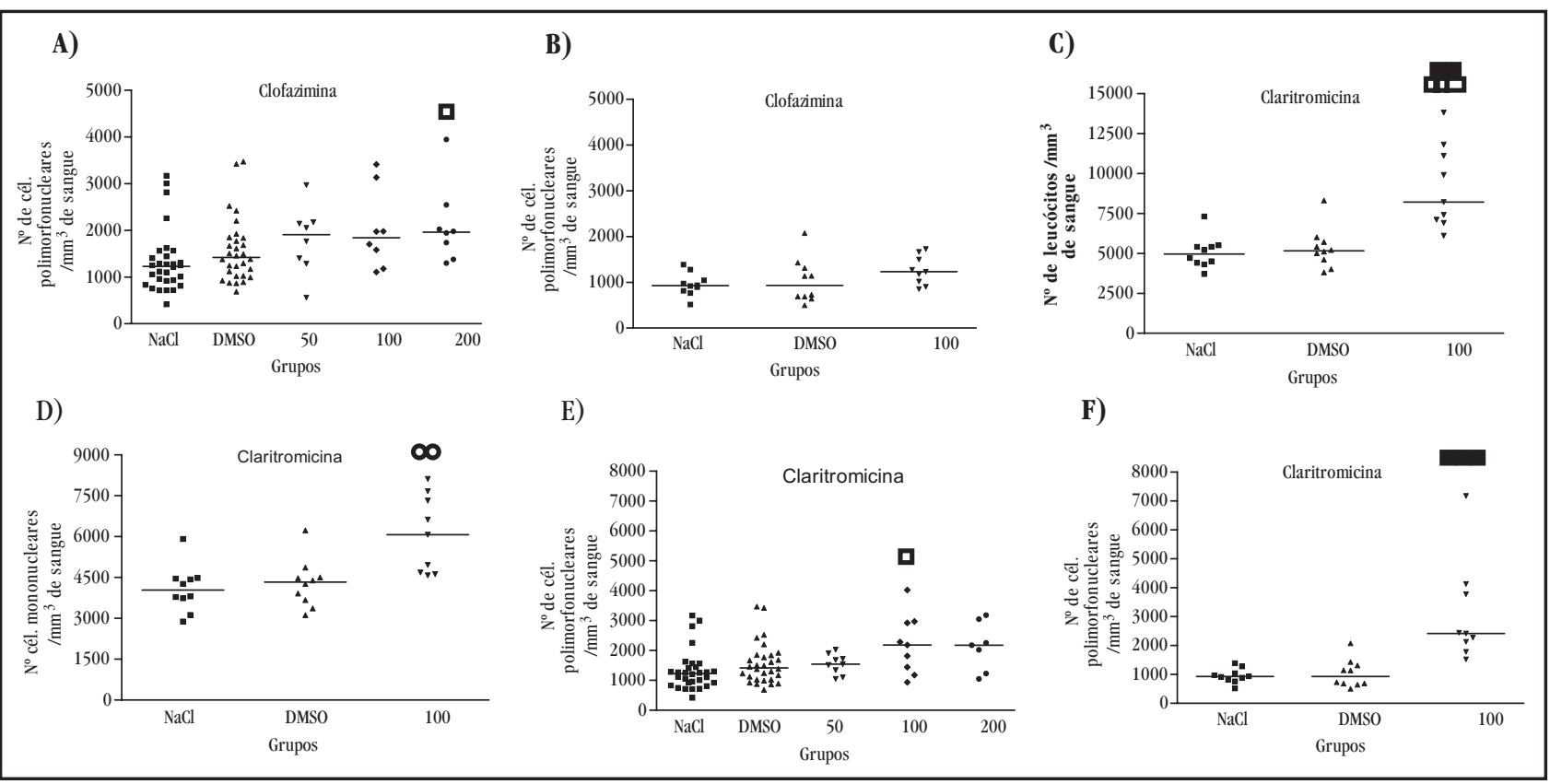

As barras representam as medianas. $\square \mathrm{p}<0,05$ em relação a NaCl 0,9\%; $\square \mathrm{p}<0,01$ em relação a DMSO; $\square \square \mathrm{p}<0,001$ em relação a NaCl 0,9\%; ${ }^{\circ}{ }^{\mathrm{p}}<0,01$ em relação a $\mathrm{NaCl} 0,9 \%$ e DMSO; $\square \mathrm{p}<0,001$ em relação a NaCl $0,9 \%$ e DMSO.

Figura 1-A: Número de células polimorfonucleares em ratos tratados com clofazimina em regime de dose única, nas doses de 50 , 100 e $200 m g / k g$ de peso. B: Em regime de dose múltipla, na dose de 100mg/kg de peso. C: Número de leucócitos em ratos tratados com claritromicina em regime de dose múltipla, na dose de 100mg/kg de peso. D: Número de células mononucleares em ratos tratados com claritromicina em regime de dose múltipla, na dose de 100mg/kg de peso. E: Número de células polimorfonucleares em ratos tratados com claritromicina em regime de dose única, nas doses de 50, 100 e 200mg/kg de peso. F: Em regime de dose múltipla, na dose de 100mg/kg de peso.

mononucleares (Figura 1D) em regime de dose múltipla, e polimorfonucleares, em ambos os regimes de dosagem (Figuras 1E e 1F). Foram observadas alterações morfológicas em células nucleadas do sangue periférico, ocasionadas por ambos os fármacos, apenas na maior dose única utilizada (Tabela 2).

Nenhum dos fármacos provocou alterações no número de plaquetas (FA Paina, RHC Queiroz, AM Souza: dados não publicados).

Parâmetros hemostáticos. Ambos os fármacos provocaram prolongamento do tempo de protrombina (TP), sendo clofazimina na dose única de $100 \mathrm{mg} / \mathrm{kg}$ (Figura 2A) e também na dose múltipla (Figura 2B), embora sem significância estatística, e claritromicina em ambos os regimes de dosagem (Figuras 2C e 2D). 0 tempo de tromboplastina parcial ativada (TTPA) se mostrou ligeiramente aumentado quando os ratos foram tratados com clofazimina (Figura 2E) e significantemente maior quando o tratamento foi feito com claritromicina, em regime de dose múltipla (Figura 2F).

Perfil hepático. Os níveis plasmáticos de aspartato aminotransferase (AST), alanina aminotransferase (ALT) e fosfatase

Tabela 2 - Porcentagem de animais com alterações em células nucleadas do sangue periférico, tratados com clofazimina e claritromicina nas doses de 50mg/kg, 100mg/kg e 200mg/kg, em esquema de doses única (du) e múltipla (dm).

\begin{tabular}{lcccccccc}
\hline & $\begin{array}{c}\text { NaCl 0,9\% } \\
\left(\mathrm{n}^{\circ}=30, \mathrm{du}\right) \\
\left(\mathrm{n}^{\circ}=10, \mathrm{dm}\right)\end{array}$ & $\begin{array}{c}\text { DMSO } \\
\left(\mathrm{n}^{0}=30, \mathrm{du}\right) \\
\left(\mathrm{n}^{0}=10, \mathrm{dm}\right)\end{array}$ & $\begin{array}{c}\text { CFZ 50 } \\
\left(\mathrm{n}^{0}=8, \mathrm{du}\right)\end{array}$ & $\begin{array}{c}\text { CFZ 100 } \\
\left(\mathrm{n}^{0}=8, \mathrm{du}\right) \\
\left(\mathrm{n}^{0}=9, \mathrm{dm}\right)\end{array}$ & $\begin{array}{c}\text { CFZ 200 } \\
\left(\mathrm{n}^{\circ}=8, \mathrm{du}\right)\end{array}$ & $\begin{array}{c}\text { CRT 50 } \\
\left(\mathrm{n}^{\circ}=9 ; \mathrm{du}\right)\end{array}$ & $\begin{array}{c}\text { CRT 100 } \\
\left(\mathrm{n}^{\circ}=9 ; \mathrm{du}\right)\end{array}$ & $\begin{array}{c}\text { CRT 200 } \\
\left(\mathrm{n}^{0}=7 ; \mathrm{du}\right)\end{array}$ \\
\hline Dose única & 16,7 & 17,9 & 0 & 20 & 60 & 0 & 20 & 71,4 \\
Dose múltipla & 10 & 30 & - & 22,2 & - & - & 40 & - \\
\hline
\end{tabular}

NaCl 0,9\%: cloreto de sódio 0,9\%, DMSO: dimetilsulfóxido, CFZ 50: clofazimina na dose de 50mg/kg, CFZ 100: clofazimina na dose de $100 \mathrm{mg} / \mathrm{kg}$, CFZ 200: clofazimina na dose de $200 \mathrm{mg} / \mathrm{kg}$, CRT 50: claritromicina na dose de $50 \mathrm{mg} / \mathrm{kg}$, CRT 100: claritromicina na dose de $100 \mathrm{mg} / \mathrm{kg}$, CRT 200: claritromicina na dose de $200 \mathrm{mg} / \mathrm{kg}$. 
alcalina sofreram variações inconclusivas provocadas por ambos os fármacos (FA Paina, RHC Queiroz, AM Souza: dados não publicados). Entretanto, os níveis plasmáticos de gamaglutamiltransferase ( $\gamma$-GT) aumentaram quando os animais foram tratados com ambos os fármacos, na maior dose única utilizada (Figuras 3A e 3B), e por claritromicina em dose múltipla (Figura 3C). Claritromicina ainda ocasionou aumento de bilirrubinas total e direta, em regime de dose única (Figuras 3D e 3E).

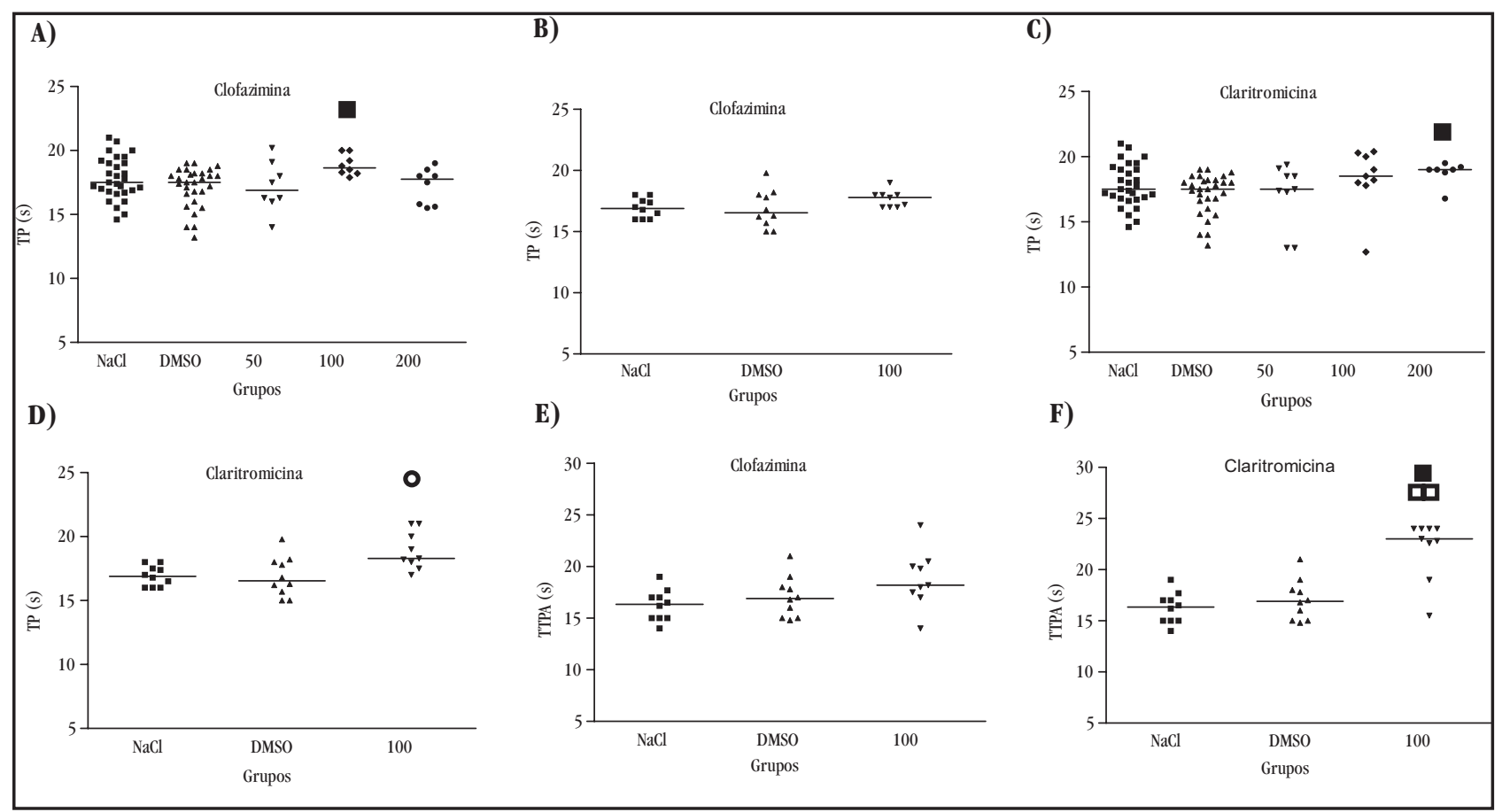

As barras representam as medianas. $\mathbf{p}<0,05$ em relação a DMSO; ${ }^{\circ} \mathrm{p}<0,05$ em relação a NaCl 0,9\% e DMSO; $\square$ p $<0,01$ em relação a NaCl $0,9 \%$.

Figura 2-A: Tempo de protrombina (TP) em ratos tratados com clofazimina em regime de dose única, nas doses de 50,100 e $200 m g / k g$ de peso. B: Em regime de dose múltipla, na dose de $100 \mathrm{mg} / \mathrm{kg}$ de peso. C: Tempo de protrombina (TP) em ratos tratados com claritromicina em regime de dose única, nas doses de 50, 100 e $200 \mathrm{mg} / \mathrm{kg}$ de peso. D: Em regime de dose múltipla, na dose de 100mg/kg de peso. E: Tempo de tromboplastina parcial ativada (TTPA) em ratos tratados com clofazimina em regime de dose múltipla, na dose de 100mg/kg de peso. F: Tempo de tromboplastina parcial ativada (TTPA) em ratos tratados com claritromicina em regime de dose múltipla, na dose de $100 \mathrm{mg} / \mathrm{kg}$ de peso.

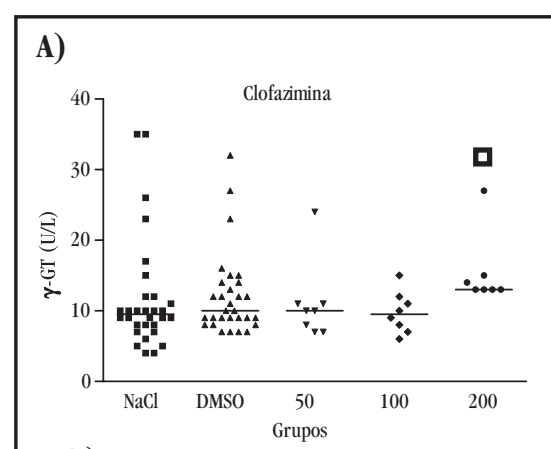

D)

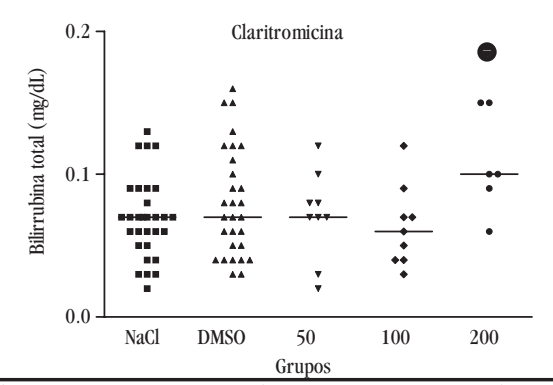

B)

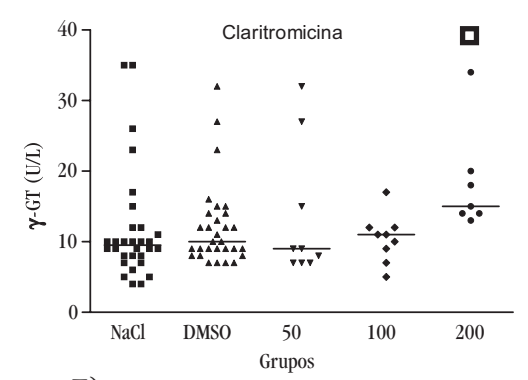

E)

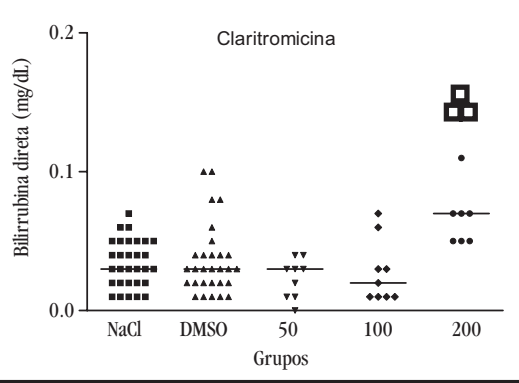

C)

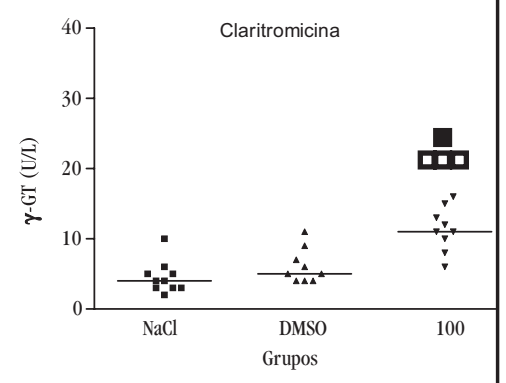

As barras representam as medianas. $\square$ p $<0,05$ em relação a NaCl 0,9\%; $\square$ p $<0,05$ em relação a DMSO; $\square \square$ p $<0,001$ em relação a NaCl $0,9 \%$; ${ }^{\bullet}$ p $<0,05$ em relação a $\mathrm{NaCl} 0,9 \%$ e $100 \mathrm{mg} / \mathrm{kg} ;{ }^{\circ} \mathrm{p}<0,01 \mathrm{em}$ relação a DMSO, $50 \mathrm{mg} / \mathrm{kg}$ e $100 \mathrm{mg} / \mathrm{kg}$.

Figura 3 - A: Níveis plasmáticos de gama-glutamiltransferase ( $\gamma$-GT) em ratos tratados com clofazimina, em regime de dose única, nas doses de 50,100 e 200mg/kg de peso. B: Níveis plasmáticos de gama-glutamiltransferase ( $\gamma$-GT) em ratos tratados com claritromicina, em regime de dose única, nas doses de 50, 100 e 200mg/kg de peso. C: Em regime de dose múltipla, na dose de 100mg/kg de peso. D: Níveis plasmáticos de bilirrubina total em ratos tratados com claritromicina em regime de dose única, nas doses de 50,100 e 200mg/kg de peso. E: Níveis plasmáticos de bilirrubina direta em ratos tratados com claritromicina em regime de dose única, nas doses de 50, 100 e $200 \mathrm{mg} / \mathrm{kg}$ de peso. 


\section{DISCUSSÃo}

Devido à escassez de relatos referentes à toxicidade de clofazimina e claritromicina, neste estudo foram avaliados os possíveis efeitos adversos destas terapias, através da avaliação de parâmetros hematológicos, hemostáticos e da função hepática. Valores anormais encontrados em animais sob tratamento podem significar alterações devido a efeitos farmacológicos e/ou toxicológicos e a avaliação de parâmetros hematológicos e bioquímicos é fundamental para a determinação destes efeitos ${ }^{16}$.

A análise da série leucocitária mostrou que clofazimina, em regime de dose única, provocou redução do número de células mononucleares, em todas as doses, embora esta diferença não seja estatisticamente significante (dados não publicados). Ocorreu aumento significante do número de células polimorfonucleares quando se utilizou a dose de $200 \mathrm{mg} / \mathrm{kg}$ (Figura 1A). Nos ratos controles, o número de células mononucleares é maior do que o das polimorfonucleares. Assim, parece que este fármaco leva a uma inversão da proporção entre células mono e polimorfonucleares, provavelmente devido à mobilização de neutrófilos marginados, visto que o tempo entre a injeção dos fármacos e controles e a coleta foi de apenas duas horas. Embora o número de polimorfonucleares não tenha variado significantemente nos grupos controles e tratado, em regime de dose múltipla (Figura 1B), observou-se uma tendência de aumento destas células, que pode estar relacionado à ação do fármaco, visto que clofazimina estimula a geração de oxidantes como 0 ânion radical superóxido nos neutrófilos ${ }^{11}$, o que contribui para a defesa do organismo contra patógenos intracelulares. A dose intermediária de $100 \mathrm{mg} / \mathrm{kg}$, tanto em regime de dose única (Figura 1A) como dose múltipla (Figura 1B), foi suficiente para ocasionar aumento do número de células polimorfonucleares, embora sem significância estatística. Em regime de dose múltipla, o tempo de exposição a a fármaco (4 dias) pode estar provocando aumento da produção de neutrófilos, visto que estas células permanecem em circulação por cerca de 8 horas. Em dose única, houve uma tendência maior de aumento em relação à dose múltipla, devendo-se considerar que, além da variabilidade biológica individual, a exposição aguda (2 horas) pode causar rápida mobilização dos neutrófilos marginados.

Claritromicina provocou redução do número de células mononucleares, em todas as doses únicas, embora estes resultados não tenham significância estatística (dados não publicados). Ocorreu aumento significativo do número de células polimorfonucleares utilizando-se claritromicina na dose de $100 \mathrm{mg} / \mathrm{kg}$ (Figura 1E). Do mesmo modo que a clofazimina, claritromicina parece também inverter a proporção entre células mono e polimorfonucleares, possivelmente pela mobilização do pool marginal de neutrófilos causada pelo fármaco, já que esta inversão não foi observada nos grupos controles. Em regime de dose múltipla, claritromicina ocasionou aumento do número de leucócitos (Figura 1C) e das células mononucleares e polimorfonucleares (Figuras 1D e 1F). De acordo com alguns estudos ${ }^{7}$, dentre os efeitos adversos observados para eritromicina, um análogo estrutural da claritromicina, está leucocitose e eosinofilia e a biópsia hepática revela infiltração periportal por neutrófilos, linfócitos e eosinófilos. Em nossos estudos, foi verificado aumento do número de células polimorfonucleares na dose intermediária de $100 \mathrm{mg} / \mathrm{kg}$, tanto em regime de dose única (Figura 1E) como dose múltipla (Figura 1F), demonstrando que, de forma análoga à clofazimina, doses mais altas deste fármaco podem provocar mobilização do pool marginal de neutrófilos, em exposição aguda, ou aumento da produção, na exposição crônica. Entretanto, pesquisadores afirmam que este quadro pode se reverter e as manifestações desaparecem dentro de poucos dias após a suspensão do tratamento ${ }^{7}$.

Ambos os fármacos provocaram prolongamento do tempo de protrombina (TP), nos dois regimes de dosagem (Figuras 2A a 2D), e prolongamento do tempo de tromboplastina parcial ativada (TTPA), em regime de dose múltipla (Figuras 2E e 2F). Wallace e colaboradores ${ }^{24}$ relataram aumento do tempo de protrombina (TP) em pacientes adultos utilizando claritromicina. Estas alterações indicam que o uso de doses mais altas destes fármacos pode provocar distúrbios da função hepática. Doenças hepáticas induzem modificações na hemostasia devido à síntese reduzida dos fatores da coagulação ou produção de proteínas qualitativamente anormais ${ }^{1}$.

Observou-se elevação dos níveis plasmáticos de gamaglutamiltransferase $(\gamma-\mathrm{GT})$, provocada pelos dois fármacos, na maior dose única utilizada (Figuras 3A e 3B). Claritromicina ainda elevou estes níveis em dose múltipla (Figura 3C), além de alterar os níveis plasmáticos de bilirrubinas total e direta em regime de dose única (Figuras 3D e 3E). A gama-glutamiltransferase, por estar presente em grandes quantidades no retículo endoplasmático liso, é susceptível à indução de aumento da sua atividade por fármacos, inclusive os antimicrobianos ${ }^{12}$. A biotransformação dos fármacos ocorre no retículo endoplasmático, o que justifica as alterações observadas por nós ${ }^{25}$. Alguns estudos indicaram aumento de bilirrubina total e disfunção hepática, inclusive colestase, em pacientes que receberam claritromicina ${ }^{6}{ }^{18}$. Há resultados mostrando que a eritromicina, um análogo estrutural da claritromicina, está entre os fármacos envolvidos com indução de colestase ${ }^{712}$.

Portanto, observamos que clofazimina e claritromicina provocam alterações tanto em parâmetros hematológicos como hemostáticos e bioquímicos, sendo que as alterações observadas nos dois últimos sugerem que estes fármacos provocam lesão hepática. Entretanto, em estudos clínicos, os efeitos adversos são passageiros, diminuindo com a redução da dosagem ${ }^{26}$ ou cessando com a suspensão do tratamento ${ }^{17}$.

As alterações das células polimorfonucleares verificadas em nosso estudo, indicam a necessidade de avaliar se a função dos neutrófilos está comprometida. Além disso, como a claritromicina é inibidora do sistema enzimático citocromo P450, torna-se importante a avaliação dos efeitos adversos provocados pela associação dos fármacos, esquema o qual é utilizado no tratamento de infecções provocadas pelo complexo Mycobacterium avium. Estas avaliações já estão sendo realizadas em nosso laboratório. 


\section{AGRADECIMENTOS}

Agradecemos o apoio técnico de Zita Maria de Oliveira Gregório, Sônia Aparecida Carvalho Dreossi e Luisa Helena Dias Costa.

\section{REFERÊNCIAS}

1. Balistreri WF, Rej R. Função hepática. In: Burtis CA, Ashwood ER (eds) Tietz: Fundamentos de Química Clínica, $4^{\text {nd }}$ edition, Guanabara Koogan, Rio de Janeiro, p. 523-551, 1998.

2. Baz K, Ikizoglu G, Yazici AC, Kokturk A, Tiftik N, Apa DD, Demirserent D. Fatal aplastic anaemia in a patient with clarithromycin-induced toxic epidermal necrolysis. Journal of the European Academy of Dermatology and Venereology 18: 104-105, 2004.

3. Bell WN, Alton HG. Brain extract as substitute for platelet suspensions in thromboplastin generation test. Nature 174: 880-881, 1954.

4. Bowers Jr GN, McComb RB. Measurement of total alkaline phosphatase activity in human serum. Clinical Chemistry 26: 1988-1995, 1975.

5. Cassell GH, Drnec J, Waites KB. Efficacy of clarithromycin against Mycoplasma pneumoniae. The Journal of Antimicrobial Chemotherapy 27: 47-59, 1991.

6. Chambers HF. Antimicrobianos. Inibidores da síntese protéica e antibacterianos diversos. I $n$ : Hardman JG, Limbird LE, Gilman AG (eds) Goodman \& Gilman, As bases farmacológicas da terapêutica, $10^{\text {nd }}$ edition, McGraw-Hill, Rio de Janeiro, p. 929-953, 2003.

7. Field SK, Cowie RL. Treatment of Mycobacterium avium-intracellulare complex lung disease with a macrolide, ethambutol, and clofazimine. Chest 124: 14821486, 2003.

8. Ji B, Jamet P, Perani EG, Bobin P, Grosset JH. Powerful bactericidal activities of clarithromycin and minocycline against Mycobacterium leprae in lepromatous leprosy. The Journal of Infectious Diseases 168: 188-190, 1993.

9. Korolkovas A, França FFAC. Dicionário Terapêutico Guanabara. Editora Guanabara Koogan, Rio de Janeiro, 2004.

10. Lemke TL. Antimycobacterial Agents. In: Foye WO, Lemke TL, Williams DA (eds) Principles of Medicinal Chemistry, $4^{\text {nd }}$ edition, Lippincott Williams \& Wilkins, Philadelphia, p. 756-757, 1995.

11. Magalhães MCC, Rojas LI. Diferenciação territorial da hanseníase no Brasil. Epidemiologia e Serviços de Saúde 16: 75-84, 2007.
12. Motta VT. Bioquímica clínica para o laboratório. Editora Médica Missau, Porto Alegre, 2003.

13. O'Connor R, O'Sullivan JF, O'Kennedy R. Determination of serum and tissue levels of phenazines including clofazimine. Journal of Chromatography B 681: 307-315, 1996.

14. Ohe M, Kohno M. Three cases of idiopathic thrombocytopenic purpura showing an increase in the platelet count following clarithromycin treatment. [Rinsh ketsueki] The Japanese Journal of Clinical Hematology 44: 1044-1066, 2003.

15. Özsoylar G, Sayin A, Bolay H. Clarithromycin monotherapy-induced delirium. The Journal of Antimicrobial Chemotherapy 5: 1-1, 2007.

16. Petterino C, Argentino-Storino A. Clinical chemistry and haematology historical data in control Sprague-Dawley rats from pre-clinical toxicity studies. Experimental and Toxicological Pathology: Official Journal of the Gesellschaft für Toxikologische Pathologie 57: 213-219, 2006.

17. Piscitelli SC, Danziger LH, Rodvold KA. Clarithromycin and azithromycin: new macrolide antibiotics. Clinical Pharmacy 11: 137-152, 1992.

18. Poirier R. Comparative study of clarithromycin and roxithromycin in the treatment of community-acquired pneumonia. The Journal of Antimicrobial Chemotherapy 27: 109-116, 1991.

19. Queiroz HHC, Souza AM, Sampaio SV, Melchior Jr E. Biochemical and hematological side effects of clofazimine in leprosy patients. Pharmacological Research: the Official Journal of the Italian Pharmacological Society 46: 191-194, 2002.

20. Quick AJ. The nature of the bleeding in jaundice. Journal of the American Medical Association 110: 1658, 1938.

21. Reitman S, Frankel SA. A colorimetric method for the determination of serum glutamic oxalacetic and glutamic piruvic transaminases. American Journal of Clinical Pathology 28: 57-63, 1957.

22. Sims FH, Horn C. Some observations on Powell's methods for the determination of serum bilirubin. American Journal of Clinical Pathology 29: 412-417, 1958.

23. Szasz G. A kinetic photometric method for serum gamma-glutamyl transpeptidase. Clinical Chemistry 15: 124-136, 1969.

24. Wallace RJ, Brown BA, Griffith DE. Reduced serum levels of clarithromycin in patients treated with multidrug regimens including rifampin or rifabutin for Mycobacterium avium-M. intracellulare infection. The Journal of Infectious Diseases 171: 747-750, 1995.

25. Wilkinson GR. Farmacocinética. Dinâmica da absorção, da distribuição e da eliminação dos fármacos. In: Hardman JG, Limbird LE, Gilman AG (eds) Goodman \& Gilman: As bases farmacológicas da terapêutica, $10^{\text {nd }}$ edition, McGraw-Hill, Rio de Janeiro, p. 3-23, 2003.

26. Yawalkar SJ, Vischer W. Lamprene (clofazimine) in leprosy. Leprosy Review 50: 135-144, 1979. 